\title{
Thermal Energy Storage System using Bamboo in Combination with PCM
}

\author{
Shoeb J. Inamdar, Umesh Patil, Hrishabh Lodam
}

\begin{abstract}
The design of a Thermal energy storage system indicates the progress being made in this field. It reflects the level of implementation of new ideas by local societies as well as the Energy policy at the National level. We are using heat storage capacity of bamboo in combination with phase changing material for space heating, bamboo has some beneficial properties like its heat storage capacity increases with increasing temperature and its conductivity too is quite slow which is why it can easily preserve heat for longer durations( nearly up to 7 to 8 hours.)

We look forward to utilize phase changing material along with bamboo for further increasing the heat storage capacity (large quantity of heat can be easily stored) of system so that we can easily achieve the sufficient temperature in order to meet human comfort conditions in all seasons(especially winter).

Space heating represents the largest end use in buildings, offices etc, and consumes more than 7 trillion Joules of site ener gy annually. With this project we intend to put the waste heat to better use by diverting it to a better heating system which includes the use of the heat storage capacity of bamboo amplified with the use of Phase Changing Material.

In this project we intend to test various PCM with bamboo to get a better option to be paired with it. The iterations being carried out on our self designed test rig are expected to give us reliable and accountable results.
\end{abstract}

Keywords : Bamboo, PCM, Heat Storage, power consumption, Thermal storage system

\section{INTRODUCTION}

Thermal energy can refer to several distinct thermodynamic quantities, such as the internal energy of a system; heat or sensible heat, which are defined as types of transfer of energy (as is work); or for the characteristic energy of a degree of freedom in a thermal system KT, where $\mathrm{T}$ is temperature is a physical quantity expressing hot and cold. It is measured with a thermometer calibrated in one or more temperature scales. The most commonly used scales are the Celsius scale (formerly called centigrade) (denoted ${ }^{\circ} \mathrm{C}$ ), Fahrenheit scale (denoted ${ }^{\circ} \mathrm{F}$ ), and Kelvin scale (denoted $\mathrm{K}$ ) and $\mathrm{K}$ is the Boltzmann constant $(\mathrm{kB}$ or $\mathrm{k}$ ) is a physical constant relating the average relative kinetic energy of particles in a gas with the temperature of the gas.

Revised Manuscript Received on July 22, 2019.

Shoeb J. Inamdar, Assistant Professor, Department of Mechanical Engineering,H.V.P.M's COET, Amravati, India

Umesh Patil, U.G Student, Department of Mechanical Engineering, H.V.P.M's COET, Amravati, India

Hrishabh Lodam, U.G Student, Department of Mechanical Engineering, H.V.P.M's COET, Amravati, India
In an 1847 lecture titled "On Matter, Living Force, and Heat", James Prescott Joule characterized various terms that are closely related to thermal energy and heat. He identified the terms latent heat and sensible heat as forms of heat each affecting distinct physical phenomenon, namely the potential energy and the kinetic energy of particles, respectively. He described latent energy as the energy of interaction in a given configuration of particles, i.e. a form of potential energy, and the sensible heat as an energy affecting temperature measured by the thermometer due to the thermal energy, which he called the living force.

As we know that heat is low grade energy that can be easily converted into various forms in order to perform various work. We can also use various thermal storage system for heat storage like PCM, sorption material etc and utilize this heat for various purpose. We are introducing bamboo in combination with PCM for heat storage because bamboo has a relatively better heat storage capacity with a comparatively low rate of thermal conductivity and hence it can store heat for longer durations.

\section{Nomenclature}

$\begin{array}{ll}\text { PCM } & \text { Phase Changing Material } \\ \text { PW } & \text { Paraffin Wax } \\ \text { MA } & \text { Myristic Acid } \\ \text { SA } & \text { Steric Acid } \\ \text { C } & \text { Specific Heat } \\ \text { r } & \text { Radius (m) } \\ \text { Subscript } & \\ \text { p } & \text { Constant Pressure } \\ \text { sf } & \text { Fusion from solid to liquid } \\ 1 & \text { At Inlet of Bamboo } \\ 2 & \text { At PCM }\end{array}$

\section{Greek Symbols}

$\Delta \quad$ Difference 


$\begin{array}{ll}\mathrm{T} & \text { Temperature }\left({ }^{\circ} \mathrm{C}\right) \\ \mathrm{h} & \text { Enthalpy }(\mathrm{KJ} / \mathrm{kg}) \\ \mathrm{m} & \text { Mass }(\mathrm{kg}) \\ \mathrm{Q} & \text { Heat }(\mathrm{KJ}) \\ \mathrm{K} & \text { Thermal Conductivity }(\mathrm{W} / \mathrm{mk}) \\ \mathrm{TES} & \text { Thermal Energy Storage System } \\ & \\ 3 & \text { At Bamboo Surface } \\ 4 & \text { At Bamboo Outlet } \\ 5 & \text { At water storage tank }\end{array}$

$\rho \quad$ Density $\left(\mathrm{kg} / \mathrm{m}^{3}\right)$

\subsection{Thermo physical properties of bamboo}

According to previous research approximately 148 species in 29 genera of bamboo are thought to found in India, out of which there are 3 large genera namely the Bambusa, the Dendrocalamus, and the Ochlandra with more than 10 species each. These three genera represent about $45 \%$ of the total bamboo species found throughout India. On the other hand, there are some genera which are represented by only one species like Sarocalamus, Ampelocalamus, etc. these all different kind of bamboo species have their own thermo physical properties. So some general thermo physical properties of bamboo are as follows:

1. Thermal conductivity of Bamboo varies from 0.12 to $0.38 \mathrm{~W} / \mathrm{m}-\mathrm{K}$ and it increases with increase in density

2. Specific heat capacity of raw bamboo increases with increase in temperature.

3. The thermal conductivity \& diffusivity of bamboo is not constant along the radial direction

4. Engineered bamboo composite have a same or lower thermal conductivity in comparison with wood of same density

\subsection{Phase changing Material}

Phase Change Material (PCM) is substance which absorbs or releases large amount of latent heat when it undergoes a change in its physical state, i.e. from solid to liquid and vice versa. PCM's are substances that absorb thermal energy during the process of melting and release the same during the process of freezing. In market different type of PCM's are available with different kind of thermal properties as a result of their chemical composition. Out of which some are as follows:
A) Paraffin wax $\left(\mathrm{C}_{31} \mathrm{H}_{64}\right)$
1. Density $=900 \mathrm{~kg} / \mathrm{m}^{3}$
2. Specific heat $=2.14-2.9 \mathrm{~J} / \mathrm{gK}$
3. Heat of fusion $=200-220 \mathrm{~J} / \mathrm{g}$
4. Melting point $=58-60^{\circ} \mathrm{C}$
B) Myristic acid $\left(\mathrm{C}_{14} \mathrm{H}_{28} \mathrm{O}_{2}\right)$
1. Density $=0.8622 \mathrm{~g} / \mathrm{cm}^{3}$
2. Specific heat $=432.013 \mathrm{~J} / \mathrm{mol}-\mathrm{k}$
3. Heat of fusion $=200-220 \mathrm{~J} / \mathrm{g}$
4. Melting point $=54.4^{\circ} \mathrm{C}$
5. Boiling point $=326.2^{\circ} \mathrm{C}$

C) Steric acid $\left(\mathrm{C}_{18} \mathrm{H}_{36} \mathrm{O}_{2}\right)$

1. Density $=0.941 \mathrm{~g} / \mathrm{cm}^{3}$

2. Specific heat $=501.5 \mathrm{j} / \mathrm{mol}-\mathrm{k}$

3. Melting point $=69^{\circ} \mathrm{C}$

4. Boiling point $=361^{\circ} \mathrm{C}$

5 . Heat of fusion $=159 \mathrm{~J} / \mathrm{g}$

\section{TeSt BenCH}

2.1 Experimental setup

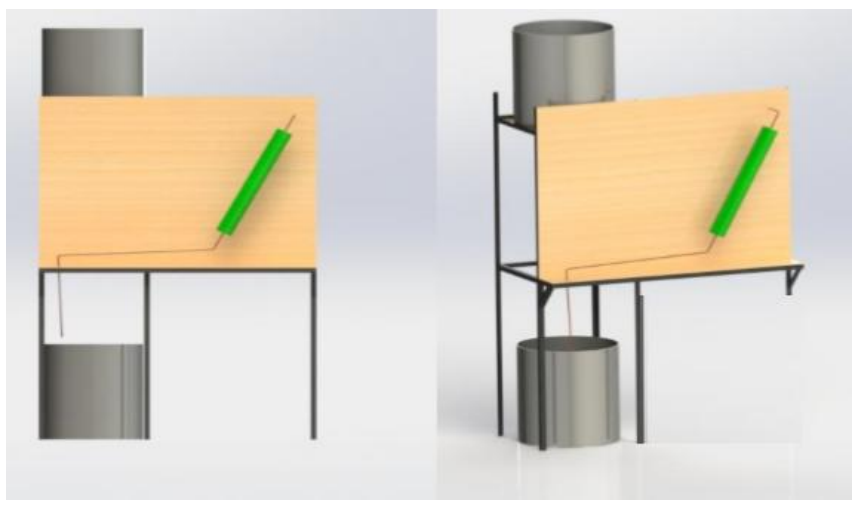

Fig. 1. Experimental Setup

The set up consists of a tank which is filled with hot water maintained at a constant temperature. The water tank is provided with the heating source and the stirrer to maintain the constant temperature. This hot water is allowed to pass through the copper tube at constant flow rate and is further passed through the bamboo which is filled with the phase changing material. Proper insulation is provided over the copper tube and the bamboo in order to avoid heat loss to obtain reliable results. A Tem perature measuring device is installed in the system that measures temperature at five different points such as the tank water, the inlet of the bamboo, the surface of the bamboo, the outlet of the bamboo, and temperature of the phase changing material.

\subsection{CFD}

CFD is carried out in ANSYS 
18.2 with FLUID FLOW(FLUENT) module to identify manner on phase changing of

PCM, also to find out the amount of heat extracted by PCM from hot water during single pass. Following meshing \& calculation parameters are used during CFD.

Element order: - Linear Relevance Center: - Coarse No. of Nodes: - 444030

No. of Elements: - 438039

Time Step Size (s): - 1

No. of Time Step: - 100

Max Iterations/ Time Step: - 1

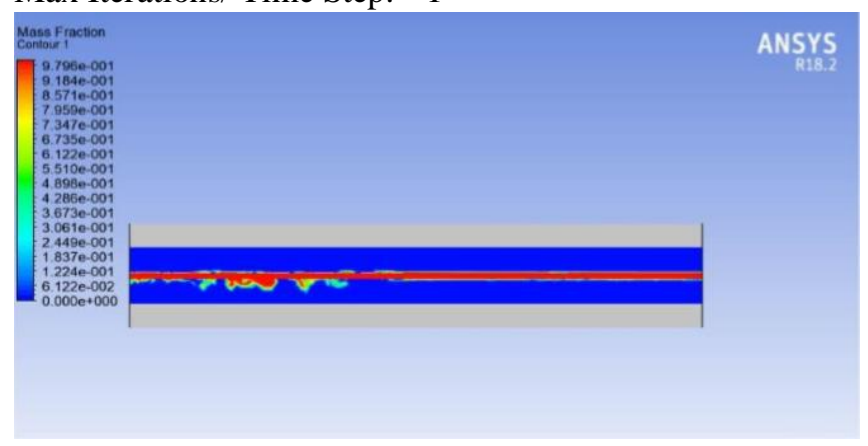

Fig. 2 CFD Simulation

\subsection{Experimental Procedure}

1. Initially the tank is filled and maintained with Hot water.

2. Then the valve is opened to allow the water to pass through the insulated copper tube which in turn flows through the bamboo filled with the PCM.

3. The PCM initially absorbs the sensible heat from hot water till it reaches its melting point.

4. After PCM reaches its melting point it starts absorbing its latent heat and starts melting. Simultaneously bamboo starts absorbing heat from PCM and reaches to the maximum Temp. i.e melting point of PCM.

*The readings are recorded by varying the combinations of two specimen of bamboo and Three PCM's namely Paraffin Wax,

Myristic Acid and Steric Acid and order to achieve reliable results under variable circumstances.

\section{OBSERVATION TABLES}

Table 1. Praffin wax $\left(\mathrm{C}_{31} \mathrm{H}_{64}\right)$

\begin{tabular}{|c|c|c|c|c|c|}
\hline Time(min) & $\mathbf{T}_{1}$ & $\mathbf{T}_{\mathbf{2}}$ & $\mathbf{T}_{\mathbf{3}}$ & $\mathbf{T}_{\mathbf{4}}$ & $\mathbf{T}_{\mathbf{5}}$ \\
\hline 15 & 69.1 & 38.7 & 36.7 & 67.5 & 70 \\
\hline 30 & 69.3 & 41.7 & 37.6 & 67.8 & 70 \\
\hline 45 & 69.2 & 44 & 38.7 & 67.9 & 70 \\
\hline 60 & 69 & 45.2 & 40 & 67.8 & 70 \\
\hline \multicolumn{7}{|c|}{ Duration increased to 30 mins. } \\
\hline 90 & 69.1 & 46.5 & 41.1 & 67.7 & 70 \\
\hline 120 & 69.3 & 48 & 41.9 & 67.9 & 70 \\
\hline 150 & 69.2 & 49.2 & 42.4 & 67.6 & 70 \\
\hline 180 & 69.4 & 51.3 & 42.8 & 67.7 & 70 \\
\hline 210 & 69.3 & 52.4 & 43.3 & 67.6 & 70 \\
\hline 240 & 69.1 & 53.1 & 43.7 & 67.2 & 70 \\
\hline 270 & 69.4 & 54.8 & 44 & 67.1 & 70 \\
\hline 300 & 69.5 & 55.4 & 44.2 & 67 & 70 \\
\hline 330 & 69.5 & 55.5 & 44.5 & 66.9 & 70 \\
\hline 360 & 69.5 & 55.5 & 44.9 & 66.7 & 70 \\
\hline
\end{tabular}

Table 2. Myristic acid $\left(\mathrm{C}_{14} \mathrm{H}_{28} \mathrm{O}_{2}\right)$

\begin{tabular}{|c|c|c|c|c|c|}
\hline Time(min) & $\mathbf{T}_{\mathbf{1}}$ & $\mathbf{T}_{\mathbf{2}}$ & $\mathbf{T}_{\mathbf{3}}$ & $\mathbf{T}_{\mathbf{4}}$ & $\mathbf{T}_{\mathbf{5}}$ \\
\hline 15 & 69.1 & 42.2 & 36.8 & 67.2 & 70 \\
\hline 30 & 69.3 & 45.4 & 37.9 & 67.3 & 70 \\
\hline 45 & 69.2 & 47.6 & 38.2 & 67.5 & 70 \\
\hline 60 & 69 & 48.4 & 38.5 & 67.7 & 70 \\
\hline \multicolumn{7}{|c|}{ Duration increased to 30 mins. } \\
\hline 90 & 69.1 & 49.3 & 39.1 & 67.9 & 70 \\
\hline 120 & 69.3 & 50.2 & 40.2 & 67.8 & 70 \\
\hline 150 & 69.2 & 51.1 & 40.7 & 67.1 & 70 \\
\hline 180 & 69.4 & 51.9 & 40.9 & 66.8 & 70 \\
\hline 210 & 69.2 & 52.1 & 41.2 & 66.4 & 70 \\
\hline 240 & 69.1 & 52.7 & 41.6 & 66.2 & 70 \\
\hline 270 & 69.4 & 52.9 & 42.1 & 66.2 & 70 \\
\hline 300 & 69.2 & 53.1 & 42.6 & 66 & 70 \\
\hline 330 & 69.3 & 53.1 & 43 & 65.7 & 70 \\
\hline
\end{tabular}


Table 3. Steric acid $\left(\mathrm{C}_{18} \mathrm{H}_{36} \mathrm{O}_{2}\right)$

\begin{tabular}{|c|c|c|c|c|c|}
\hline Time(min) & $\mathbf{T}_{\mathbf{1}}$ & $\mathbf{T}_{\mathbf{2}}$ & $\mathbf{T}_{\mathbf{3}}$ & $\mathbf{T}_{\mathbf{4}}$ & $\mathbf{T}_{\mathbf{5}}$ \\
\hline 15 & 85.2 & 40 & 38.1 & 83.2 & 85 \\
\hline 30 & 85.3 & 44.7 & 38.4 & 83.4 & 85 \\
\hline 45 & 85.1 & 51.2 & 38.9 & 83.7 & 85 \\
\hline 60 & 85.5 & 57.7 & 39.5 & 83.1 & 85 \\
\hline \multicolumn{7}{|c|}{ Duration increased to 30 mins. } \\
\hline 90 & 85.1 & 60.8 & 40.9 & 83.5 & 85 \\
\hline 120 & 85.4 & 61.9 & 41.3 & 83.8 & 85 \\
\hline 150 & 85.3 & 62.7 & 42.1 & 83.9 & 85 \\
\hline 180 & 85.1 & 63.2 & 42.3 & 84.1 & 85 \\
\hline 210 & 85.3 & 63.9 & 42.6 & 84.3 & 85 \\
\hline 240 & 85.2 & 64.1 & 43.1 & 84.1 & 85 \\
\hline 270 & 85 & 64.8 & 43.7 & 83.9 & 85 \\
\hline 300 & 85.2 & 65.1 & 43.9 & 83.8 & 85 \\
\hline 330 & 85 & 65.3 & 44.1 & 83.4 & 85 \\
\hline 360 & 85.1 & 65.3 & 44.7 & 83.1 & 85 \\
\hline
\end{tabular}

\section{SAMPLE CALCULATIONS TOTAL HEAT STORED A) PARAFFIN WAX (C31H64)}

Total heat $=($ sensible heat $) \mathrm{PCM}+($ latent heat $) \mathrm{PCM}+$ (heat)bamboo

$$
\begin{aligned}
& \mathrm{Q}=(\mathrm{mcp} \Delta \mathrm{T}) \mathrm{pcm}+\mathrm{mhsf}+(\mathrm{mcp} \Delta \mathrm{T}) \text { bamboo } \\
& \mathrm{Q}=0.5 \times 2.5 \times \quad(55.5-35.2)+0.5 \times 210+1.61 \times 1.66 \times
\end{aligned}
$$$$
\text { (44.9-35.3) }
$$$$
\mathrm{Q}=155.78 \mathrm{KJ}
$$

\section{B) Myristic acid (C14H28O2)}

Total heat $=($ sensible heat $) \mathrm{PCM}+($ latent heat $) \mathrm{PCM}+$ (heat)bamboo

$\mathrm{Q}=(\mathrm{mcp} \Delta \mathrm{T}) \mathrm{pcm}+\mathrm{mhsf}+(\mathrm{mcp} \Delta \mathrm{T})$ bamboo

$\mathrm{Q}=0.5 \times 4.3201 \times \quad(53.1-35.4)+0.50 \times 200+1.61 \times 1.66 \times$ $(43-35.6)$

\section{$\mathrm{Q}=158.01 \mathrm{KJ}$}

C) Steric acid (C18H36O2)

Total heat=(sensible heat)PCM +(latent heat)PCM + (heat)bamboo

$\mathrm{Q}=(\mathrm{mcp} \Delta \mathrm{T}) \mathrm{pcm}+\mathrm{mhsf}+(\mathrm{mcp} \Delta \mathrm{T})$ bamboo

$\mathrm{Q}=0.500 \times 5.015 \times \quad(65.3-35.2)+0.500 \times 159+1.61 \times 1.66 \times$ (44.7-35.6)

$\mathrm{Q}=179 \mathrm{KJ}$

\section{RESUltS AND ANALYSIS}

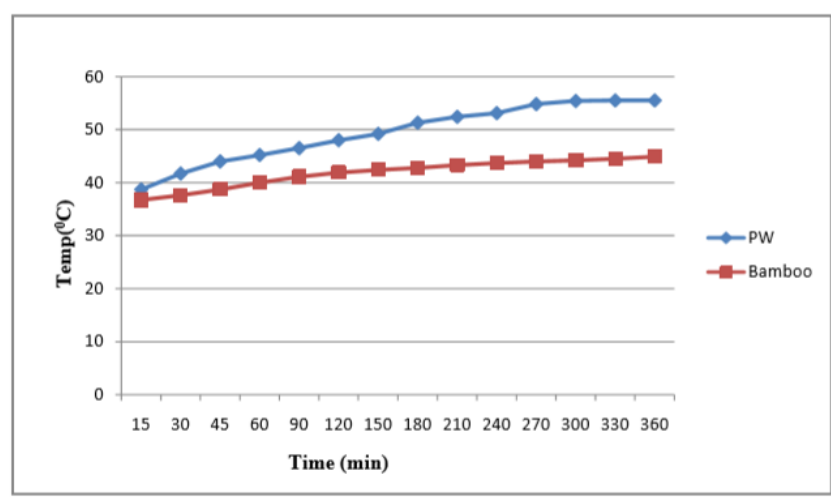

(a)

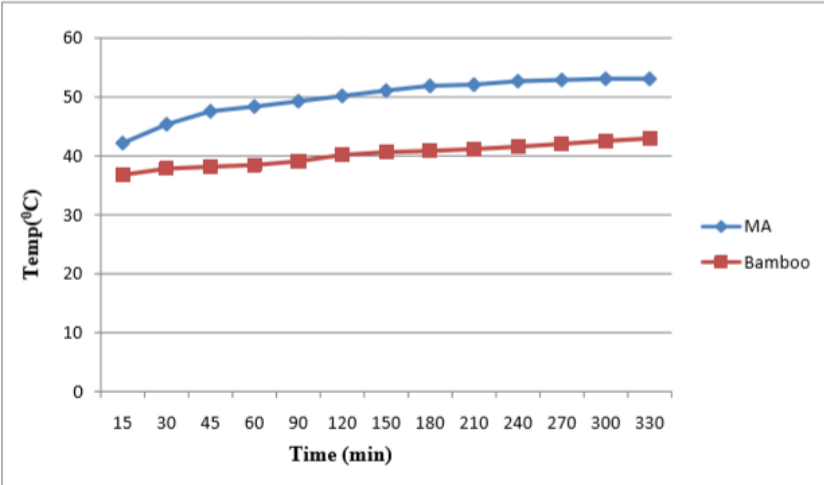

(b)

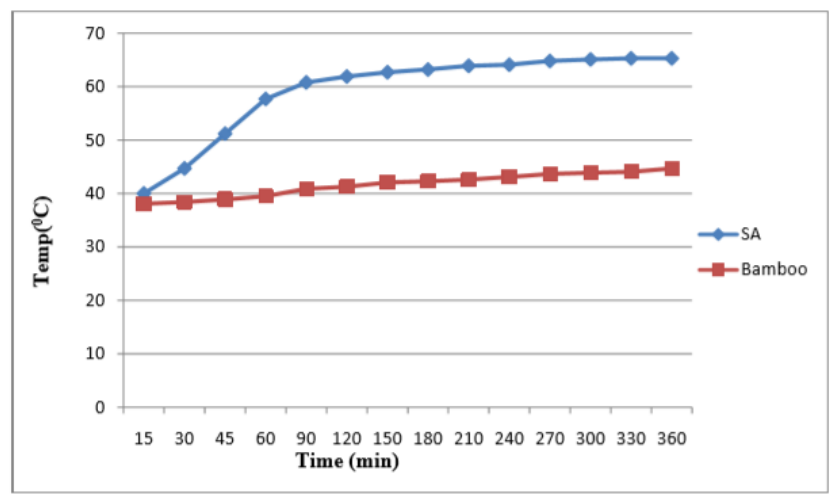

(c)

Fig. 2. Time Vs Temp plot of PCM and Bamboo (a) Paraffin Wax (b) Myristic Acid (c) Steric Acid

As the graphs indicated that as the heat is supplied to the combine system of bamboo and PCM the temp. of both increases and initially the PCM absorbs the sensible heat and later on as it reaches to its melting point it start absorbing its latent heat. Bamboo continues to absorb it's sensible heat and as can be seen from the graphs that the bamboo absorb heat to slowly and reaches to the maximum temp. of melting point of PCM. The heat is transferred to PCM from flowing hot water as convection as the conduction resistance of the copper tube can be easily neglected and so is transferred to bamboo as conduction to bamboo from PCM as the gap between these two is not that large and to convection is rarely to happen.

The heat is transferred as 
radial conduction from water to PCM then to Bamboo.

$$
Q=\frac{\Delta T}{\frac{\ln \left[\left(\frac{r}{r_{1}}\right)\right.}{2 \pi k l}}
$$

The time required in this operation is relatively high as the mass flow rate of hot water is maintained smaller and the PCM $h$ as high heat capacity as it takes time to absorb that much heat.

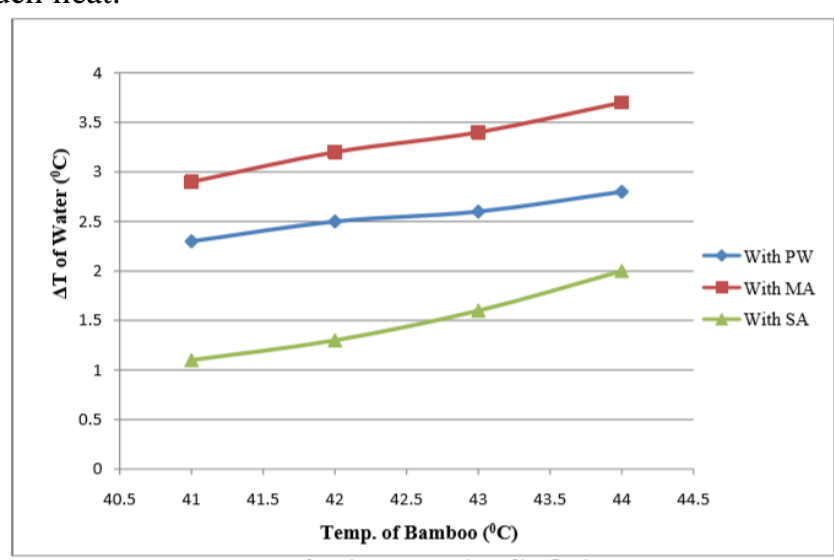

Fig. 3. Temp of Bamboo Vs Temp. drop of hot flowing water

The analysis in fig. 2 sows the variation of the temp. drop of hot water flowing with the increase temp.of bamboo. The above observations are recorded when the PCM has already achieved its maximum temp. and the PCM has completed utilized it's latent heat and completely changed its phase, this leads us to direct conclusion that whatever heat which will be added further will be absorbed by the bamboo. The heat added by the hot flowing water now will be conducted as the phase change is completed and the heat will be absorbed by the bamboo. With the increase in Temp. of bamboo the molecular activities in bamboo increases and the amount of molecular diffusion increases as a result bamboo starts absorbing more heat.

$$
Q=\mathrm{m} C \Delta T
$$

Hence the heat absorbing capacity of bamboo increases with increase in its Temperature. It depicts that the Heat capacity of the

bamboo increases with its Temperature. The observation is shown for bamboo with all three PCMs i.e PW,MA,SA all cases verifies the same behavior.

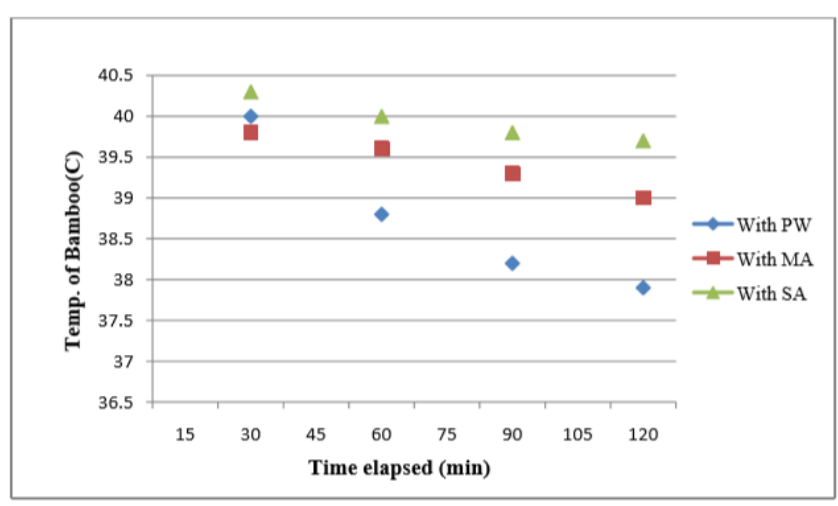

Fig. 4 Temp. of Bamboo Vs Time elapsed
After the observations are recorded and the experimentations are performed then the system is shut off. then the system comes in dead state and then the drop in temp. of bamboo is recorded with the time elapsing. Bamboo outer surface is provide $\mathrm{d}$ with simple insulation. as can be seen from the above graph that the decrease in temp.of bamboo with the time is very small a s the bamboo can trap heat for more time. The bamboo is filled with PCM and as the bamboo releases heat very slowly hence it also regulate the heat flow from PCM in discharging. This makes the thermal energy storage system very durable and heat can be stored for longer time duration.

\section{Conclusion}

In this study, the experimentation is performed on the bamboo in combination with PCM and certain results are found after successive regressions. The data so collected is verified by changing the PCM material. After performing the experimentation the following conclusions can be drawn.

1. The bamboo works good in combination with PCM.

2. Heat storing capacity of bamboo increases with increase in its temperature.

3. Bamboo releases heat very slowly hence make the whole TES very durable.

\section{REFERENCES}

1. Abhat A. Low temperature latent heat thermal energy storage: heat storage materials. Sol Energy 1983;30:313-32.

2. Castell A, Solé C. An overview on design methodologies for liquid-solid PCM storage systems. Renew Sustain Energy Rev 2015;52:289-307. [12/01/2015].

3. Ibrahim NI, Al-Sulaiman FA, Rahman S, Yilbas BS, Sahin AZ. Heat transfer enhancement of phase change materials for thermal energy storage applications: a critical review. Renew Sustain Energy Rev 2017;74:26-50. [2017/07/01/].

4. Khan MMA, Saidur R, Al-Sulaiman FA. A review for phase change materials (PCMs) in solar absorption refrigeration systems. Renew Sustain Energy Rev 2017;76:105-37. [2017/09/01/].

5. Safari A, Saidur R, Sulaiman FA, Xu Y, Dong J. A review on supercooling of phase change materials in ther mal energy storage systems. Renew Sustain Energy Rev 2017;70:905-19. [2017/04/01/].

6. Pereira J, da Cunha, Eames P. Thermal energy storage for low and medium temperature applications using phase change materials - A review. Appl Energy 2016;177:227-38. [2016/09/01/].

7. Tay NHS, Liu M, Belusko M, Bruno F. Review on transportable phase change material in thermal energy storage systems. Renew Sustain Energy Rev 2017;75:264-77. [2017/08/01/].

8. Zhou Z, Zhang Z, Zuo J, Huang K, Zhang L. Phase change materials for solar thermal energy storage in residential buildings in cold climate. Renew Sustain Energy Rev 2015;48:692-703. [2015/08/01/].

9. Muhammad M. Review of PCMS and heat transfer enhancement methods applied in parabolic trough solar plants thermal storage systems. Niger J Technol 2018;37.

10. Kenisarin M, Mahkamov K. Solar energy storage using phase change materials. Renew Sustain Energy Rev 2007;11:1913-65.

11. Farid MM, Khudhair AM, Razack SAK, Al-Hallaj S. A review on phase change energy storage: materials and applications. Energy Convers Manag 2004;45:1597-615.

12. Agyenim F, Hewitt N, Eames P, Smyth M. A review of materials, heat transfer and phase change problem formulation for latent heat thermal energy storage systems (LHTESS). Renew Sustain Energy Rev 2010;14:615-28.

13. Long Jibo, Thermal and Moisture Stress Analysis of Bamboo Buildings Based on Heat and Mass Transfer Method of Porous Medium [D]. Hunan University, 2013.

ISO 15148:2002(E): Hygrothermal performance of building materials and products - Determination of water absorption coefficient by partial immersion[S]. 